\title{
Reassessing the Safety Profile of Lesinurad in Combination with Xanthine Oxidase Inhibitor Therapy
}

Fernando Perez-Ruiz - Tim L. Jansen • Anne-Kathrin Tausche •

Pascal Richette · Frédéric Lioté $\cdot$ Alexander K. So · Austin Stack

Received: December 15, 2018 / Published online: February 14, 2019

(C) The Author(s) 2019

\section{ABSTRACT}

Introduction: The rate of adverse renal events has been shown to be higher in patients treated with lesinurad plus a xanthine-oxidase inhibitor (XOI) than in patients treated only with a XOI. We reassessed the risks for various adverse renal events from a different perspective and devised a hypothesis to explain the results.

Methods: We used data from phase 3 trials that were publicly available from the full prescribing information document and estimated the relative risk and the number needed to treat for increased serum creatinine (sCri), renal failure, and renal lithiasis. We examined these risks for

Enhanced Digital Features To view enhanced digital features for this article go to https://doi.org/10.6084/ m9.figshare.7637195.

\section{F. Perez-Ruiz ( $\square)$}

Rheumatology Division, Cruces University Hospital, Biocruces Bizkaia Health Research Institute and Medicine Department, Medicine and Nursery

School, University of the Basque Country, Bilbao,

Vizcaya, Spain

e-mail: fernando.perezruiz@osakidetza.eus

\section{T. L. Jansen}

Department of Rheumatology, VieCuri MC, Teglseweg 210, 9012 BL Venlo, The Netherlands

A.-K. Tausche

Department of Rheumatology, University Clinic

"Carl Gustav Carus" at the Technical University, Dressden, Germany each treatment group and the risks stratified by estimated glomerular filtration rate (eGFR).

Results: Overall, the relative risk for sCri was $>1.0$ with the $400 \mathrm{mg} /$ day dose of lesinurad and higher with the $200 \mathrm{mg} /$ day dose, but it was $<1.0$ for both lithiasis and renal failure with the $200 \mathrm{mg} /$ day dose. The relative risk was only statistically significant for sCri with the highest dose of lesinurad. When results stratified by eGFR were considered, the rates of adverse events increased with declining renal function, but the relative risks decreased in parallel, as the rate of adverse events increased much more in the placebo arm than in the active arm (200 $\mathrm{mg} /$ day dose). Indeed, the relative risk was only significant for the highest dose of lesinurad in patients with normal eGFR.

Conclusion: The rate of sCri events was higher in patients treated with both lesinurad and a XOI

\section{P. Richette · F. Lioté}

Rheumatology Department and Inserm URM 1132, Centre Viggo Petersen, Hôpital Lariboisière (AP-HP) and Université Paris Diderot, USPC, Paris, France
A. K. So
University of Lausanne, Lausanne, Switzerland
A. Stack
Nephrology Division, University Hospital Limerick, Graduate Entry Medical School, Health Research Institute, University of Limerick, Limerick, Ireland 
rather than a XOI alone. This rate was found to increase with decreasing eGFR, but as it does in for both active and placebo armsthe relative risk is not different from that observed in the placebo arms in the labeled $200 \mathrm{mg} /$ daydose. This may be explained by pathophysiological changes that develop in chronic kidney disease.

Keywords: Creatinine increase; Gout; Lesinurad; Safety; Relative risk; Renal failure; Renal lithiasis

\section{INTRODUCTION}

Lesinurad is a selective uric acid reabsorption inhibitor (SURI) medication that was recently approved by the European Commission following a positive evaluation from the European Medicines Agency (EMA) of the European Union and the United States Food and Drug Administration (FDA) [1]. Lesinurad exerts its urate-lowering action by selectively inhibiting urate transporters (principally URAT-1 and OAT-4) in the proximal renal tubule and blocking uric acid reabsorption, thereby increasing net uric acid renal excretion [2].

The safety profile panel established during the clinical development of lesinurad included renal events, as would be expected for any uricosuric medication. Renal events were classified as increases in serum creatinine ( $\mathrm{sCr}$ ) concentrations above baseline, renal failure (which encompassed a broad range of events, including acute or chronic renal failure and acute pre-renal failure), or nephrolithiasis. Renal events, and specifically increases in $\mathrm{sCr}$ concentration, were more frequent in patients on lesinurad than in those on a placebo (PBO), with a dosedependent relationship [3], and these events were more common in patients who did not receive a xanthine oxidase inhibitor (XOI) while on lesinurad therapy [4] and in those with moderate kidney impairment [5]. These findings led the EMA and FDA to approve lesinurad only when used in combination with a XOI and at a dose of $200 \mathrm{mg} /$ day, and to recommended that it should/must not be initiated in patients with an estimated glomerular filtration rate (eGFR) below $45 \mathrm{~mL} / \mathrm{min} / 1.73 \mathrm{~m}^{2}$ (summary of product characteristics or SmPC, FDA) [6] or $30 \mathrm{~mL} / \mathrm{min} / 1.73 \mathrm{~m}^{2}$ (SmPC, EU) [7] per minute.

Intriguingly and importantly, even though elevations in SCR were more common in lesinurad-treated patients than in those receiving a placebo, the incidence rates of renal failure and renal nephrolithiasis did not differ between these groups, although patients with a previous history of renal lithiasis were not excluded [8]. While several hypotheses have been proposed for the development of elevated sCR in lesinurad-treated patients, there is no widely accepted explanation for this occurrence. Consequently, recommendations are lacking in risk assessments of patients who may be at risk of adverse renal events when treated with lesinurad combination therapy.

Our objective was to reassess the relative risks of various adverse renal events in lesinurad-treated patients from three pivotal placebocontrolled combination clinical trials stratified according to renal function; to review, critique, and attempt to explain the results; and to propose monitoring strategies.

\section{METHODS}

We analyzed data from three major phase 3 clinical trials that tested the efficacy and safety of lesinurad in clinical practice. Incidence rates of adverse renal events were derived from Tables 2 and 3 in the full prescribing information for Zurampic [6].

Table 2 of the prescribing information shows data on the incidence rates of adverse renal events in all three major placebo-controlled clinical studies (CLEAR 1, CLEAR2, and CRYSTAL) in which lesinurad in combination with a XOI (either allopurinol or febuxostat) was compared with XOI alone [9-11]. Adverse renal events were defined as follows: (1) increased blood creatinine, defined as a greater than 1.5-fold increase in $\mathrm{sCr}$ as compared to the baseline measurement at trial entry; (2) renal failure (a composite term that described any occurrence of acute or chronic renal failure and acute prerenal failure); and (3) nephrolithiasis. The three studies together provided 516, 511, and 510 patients in the XOI + $\mathrm{PBO}, \quad \mathrm{XOI}+$ lesinurad $200 \mathrm{mg} /$ day, and XOI + lesinurad $400 \mathrm{mg}$ /day groups, respectively. 
Table 3 of the SmPC for Zurampic includes data on the occurrence of adverse events in all three clinical trials according to study arm (XOI + PBO, $\quad n=510 ; \quad$ XOI + lesinurad $200 \mathrm{mg} /$ day, $n=509 ; \quad$ and $\mathrm{XOI}+$ lesinurad $400 \mathrm{mg} /$ day, $n=508$ ) and stratified by baseline renal function category $(\geq 90, \geq 60$ to $<90$, $\geq 30$ to $<60 \mathrm{~mL} / \mathrm{min} / 1.73 \mathrm{~m}^{2}$ ).

\section{Statistical Analysis}

We determined the patient-year exposure for each study arm from a recently published report on the safety of lesinurad [3] as 408, 396, and 390 patient-years, respectively. These values were then used to compute the incidence rate of each adverse renal event stratified by GFR category ( $\geq 90 \mathrm{~mL} / \mathrm{min}, \geq 60$ to $<90 \mathrm{~mL} / \mathrm{min}, \geq 30$ to $<60 \mathrm{~mL} / \mathrm{min} / 1.73 \mathrm{~m}^{2}$ ) in each treatment arm.

Risk ratios (RRs) and numbers needed to treat (NNTs) were calculated to determine the impact of each treatment on the rates of each specified adverse renal event. Harm was defined as RR $>1$ and benefit as $R R<1$. Calculations were performed using the MedCalc software (Medcalc Software bvba, Ostend, Belgium, https://www. medcalc.org/calc/relative_risk.php). These analyses were repeated to determine the RRs of adverse renal events stratified by kidney function. When the RR for a study cannot be calculated because there are no events in the control group of a study and the standard errors cannot be computed, it is customary to add 0.5 to each cell of the $2 \times 2$ contingency table [12].

\section{Compliance with Ethics Guidelines}

Data were retrieved from a public resource: the full prescribing information for Zurampic. This article does not contain any studies with human participants or animals performed by any of the authors.

\section{RESULTS}

The incidence of increased sCr was numerically higher among patients allocated to LES $200 \mathrm{mg}$ daily than among patients allocated to a placebo ( $4.3 \%$ vs. $2.3 \%$ respectively). The corresponding RR $(1.85,0.93-3.70)$ was not statistically significant (Table 1). In contrast, patients allocated to the LES $400 \mathrm{mg}$ dose showed a significantly higher incidence of increased sCR than patients on a placebo, along with a statistically significant RR of 3.37 (1.79-6.35) (Table 1).

On the other hand, the incidence rates for renal failure and nephrolithiasis were numerically lower for the $200 \mathrm{mg}$ daily dose vs. PBO, but this was not a statistically significant difference. Similarly, patients allocated to the LES $400 \mathrm{mg}$ dose experienced rates of renal failure and nephrolithiasis that were not significantly different from those in the placebo arm (Table 1). The analysis of adverse renal events according to eGFR category is presented in Table 2. For each GFR category, the rate of increased sCR was numerically higher for the LES $200 \mathrm{mg}$ group than for the placebo arm (3.0, 3.8 , and 6.9 vs. $0.6,1.7$, and 5.9 for patients in the categories $\mathrm{CrCl} \geq 90, \mathrm{CrCl} \geq 60$ to $\leq 90$, and $\mathrm{CrCl} \geq 30$ to $\leq 60 \mathrm{~mL} / \mathrm{min}$, respectively) but there were no statistically significant differences. Intriguingly, the RR of increased sCR decreased with worsening GFR, from 5.34 for patients with $\mathrm{CrCl} \geq 90 \mathrm{~mL} / \mathrm{min}$ to 1.17 for patients with $\mathrm{CrCl} \geq 30$ to $\leq 60 \mathrm{~mL} / \mathrm{min}$; the number needed to treat was over 100 for the latter group. Furthermore, analysis of the RR of renal failure revealed a similar pattern, with the RR decreasing from 6.30 in patients with $\mathrm{CrCl} \geq 90 \mathrm{~mL} / \mathrm{min}$ to 0.40 for patients with $\mathrm{CrCl} \geq 30$ to $\leq 60 \mathrm{~mL} / \mathrm{min}$. The $\mathrm{RR}$ of renal failure for the LES $200 \mathrm{mg}$ group versus the placebo group was not statistically significant.

Compared to the placebo group, patients treated with XOI plus LES $400 \mathrm{mg}$ daily presented significantly higher incidence rates of increased SCR $(5.9,9.9$, and 10.9 vs. 0.6, 1.7, and 5.9 for patients in the categories $\mathrm{CrCl} \geq 90 \mathrm{~mL}, \mathrm{CrCl} \geq 60$ to $\leq 90$, and $\mathrm{CrCl}$ $\geq 30$ to $\leq 60 \mathrm{~mL} / \mathrm{min}$, respectively). Differences between groups did not reach statistical significance in the lower estimated glomerular filtration rate strata, as the magnitude of the risk ratio decreased with worsening GFR, from 10.64 $(1.40-81.03)$ to $5.64(1.97-16.18)$ to 1.83 (0.69-4.84). A similar pattern was observed for 
Table 1 Overall incidence rates of adverse renal events in phase III clinical trials comparing lesinurad plus XOI to placebo plus XOI

\begin{tabular}{|c|c|c|c|c|c|}
\hline & $\begin{array}{l}\text { XOI + PBO } \\
N=516 \\
\text { Events (\%) }\end{array}$ & $\begin{array}{l}\text { XOI + LES200 } \\
N=511 \\
\text { Events (\%) }\end{array}$ & RR (95\% CI) & NNT & $p$ \\
\hline Increased $s \mathrm{Cr}$ & $12(2.3)$ & $22(4.3)$ & $1.85(0.93-3.70)$ & -51 & 0.081 \\
\hline Renal failure & $11(2.1)$ & $6(1.2)$ & $0.55(0.20-1.48)$ & +104 & 0.236 \\
\hline \multirow[t]{2}{*}{ Nephrolithiasis } & $9(1.7)$ & $3(0.6)$ & $0.34(0.09-1.24)$ & +86 & 0.101 \\
\hline & $\begin{array}{l}\mathrm{XOI}+\mathrm{PBO} \\
N=516 \\
\text { Events }(\%)\end{array}$ & $\begin{array}{l}\text { XOI + LES400 } \\
N=510 \\
\text { Events (\%) }\end{array}$ & RR (95\% CI) & NNT & $p$ \\
\hline Increased $s \mathrm{Cr}$ & $12(2.3)$ & $40(7.8)$ & $3.37(1.79-6.35)$ & -18 & $<0.000$ \\
\hline Renal failure & $11(2.1)$ & $18(3.5)$ & $1.65(0.79-3.47)$ & -72 & 0.182 \\
\hline Nephrolithiasis & $9(1.7)$ & $13(2.5)$ & $1.46(0.63-3.39)$ & -124 & 0.377 \\
\hline
\end{tabular}

Increased $s C r$ serum creatinine $>1.5 \times$ baseline value, $R R$ relative risk or risk ratio (absolute risk of an event in the active group/absolute risk for event in the control group), NNT number needed to treat ( - for harm, + for benefit), XOI xanthine oxidase inhibitor, PBO placebo, LES200 lesinurad $200 \mathrm{mg}$ once a day, LES400 lesinurad $400 \mathrm{mg}$ once a day

renal failure. Figure 1 provides a visual representation of the incidence of increased SCR and the corresponding risk ratio for each treatment allocation stratified by GFR category.

\section{DISCUSSION}

Using data released publicly for use by healthcare providers [6], this analysis found that the rate of adverse renal events was not significantly different for the LES $200 \mathrm{mg}$ group and the placebo group. While the incidence of increased SCR showed a modest increase for the LES $200 \mathrm{mg}$ group as compared to the placebo group, the incidence rates of renal outcomes other than increased serum creatinine (sCri: renal failure and nephrolithiasis) were numerically lower for the LES $200 \mathrm{mg}$ arm than for the placebo arm, with none of these differences between groups being statistically significant. In contrast, treatment with the higher LES $400 \mathrm{mg}$ dose yielded significantly higher rates of increased sCR compared to the placebo group, but-surprisingly-no significantly increased risk of renal failure of nephrolithiasis. In general, adverse renal event rates were lowest among patients with normal renal function rather than among those with decreased GFR. However, we observed that the rate of adverse renal events with increased SCR rose at a faster rate in the placebo arm than in the LES $200 \mathrm{mg}$ and $400 \mathrm{mg}$ arms with worsening GFR, leading to a reduction in the relative risk.

It should be noted that while the elevation of serum creatinine from the baseline was measured as part of a safety analysis performed by the sponsor, clinical diagnoses were made by the investigators and compiled using predefined preferred terms to compile renal safety reports and included as supplemental material in [3]. Another limitation inherent to this analysis is that it is not a meta-analysis. While such a metaanalysis including five clinical trials was recently reported [13], it did not provide any fresh perspective on the optimal clinical approach to the safety of lesinurad or insight into pathophysiological mechanisms. Another limitation of our study is the fact that we could only use publicly available data compiled from phase 3 trials, and that the number of events was small.

Therefore, to evaluate the risk of adverse renal events between the placebo and active arms, we employed the relative risk or risk ratio, 
Table 2 Analysis of adverse renal events in patients stratified by estimated glomerular filtration rate

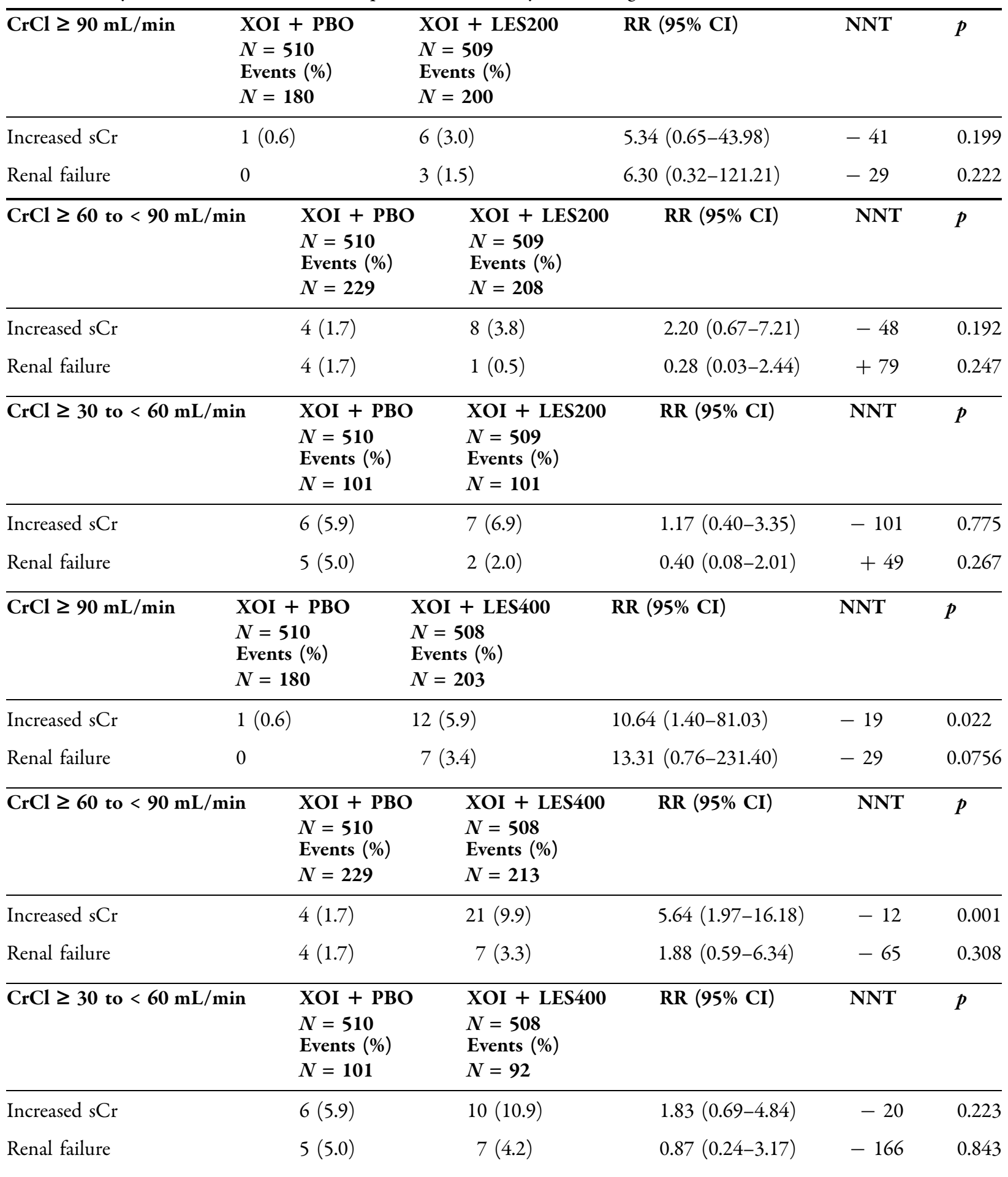

$\mathrm{CrCl}$ creatinine clearance, Increased $s \mathrm{Cr}$ serum creatinine more than $1.5 \times$ baseline value, $R R$ relative risk or risk ratio (absolute risk for the event in the active group/absolute risk for the event in the control group), NNT number needed to treat ( - for harm, + for benefit), XOI xanthine oxidase inhibitor, PBO placebo, LES200 lesinurad $200 \mathrm{mg}$ once a day, LES400 lesinurad $400 \mathrm{mg}$ once a day 


\section{RATES (\%) AND RISK RATIOS (RR) FOR SCR INCREASED \\ (>1.5*BASELINE) BY STRATA OF CRCL \\ $\square \mathrm{PBO} \square \mathrm{LES} 200$ \\ LES400}
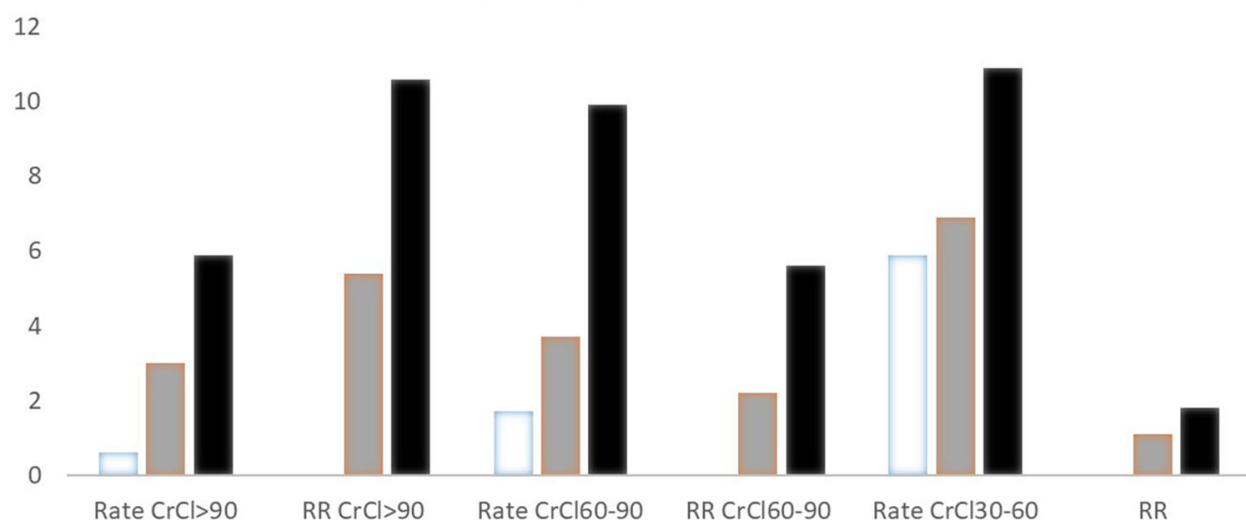

Fig. 1 Plot showing that the incidence rate of increased serum creatinine increased with decreasing eGFR, but that the RR decreased with decreasing eGFR (because the

incidence rate of increased serum creatinine increases more rapidly with decreasing eGFR in the $\mathrm{PBO}$ arm than in the LES arms). $R R$ relative risk, $P B O$ placebo, $L E S$ lesinurad

as recommended by the Cochrane collaboration to evaluate interventions [12]. Patient-year exposure was similar for all groups, as was the number of patients allocated to each group, thus facilitating unbiased estimates.

In each analysis, we found that the RRs for LES $200 \mathrm{mg}$ vs. placebo and LES $400 \mathrm{mg}$ vs placebo decreased substantially with worsening kidney function, suggesting that the risk of adverse renal events diminished or was eliminated in patients with moderate kidney impairment. If lesinurad exhibited direct nephrotoxicity [5], an increased risk of adverse events in patients with the worst kidney function would be expected, as happens with NSAIDs [14]. In contrast, we observed a pattern of decreasing relative risk of adverse renal events with decreasing eGFR, suggesting that chronic kidney disease (CKD) is associated with pathophysiological changes that may protect against any potential nephrotoxicity associated with lesinurad/XOI combinations. By contrast, the US [6] and EU [7] recommend either not prescribing in some patients with moderate renal impairment (GFR $<45 \mathrm{ml} / \mathrm{min}$ ) or taking special precautions if it is prescribed, respectively.

Risk factors for adverse renal events associated with the use of uricosuric medications include the filtered load of uric acid (the

product of the serum urate concentration $\times$ GFR), urinary $\mathrm{pH}$ (related to the acidification capacity), and urinary acid concentration (related to the concentration capacity). Indeed, higher clearance of uric acid (associated with better renal function) and undissociated urinary urate (related to both acidic urinary $\mathrm{pH}$ and the urinary uric acid concentration) have both been associated with an increased risk of nephrolithiasis during uricosuric treatment in monotherapy [15]. Moreover, the appearance of altered urine sediment, namely the presence of red cells, while starting uricosuric medications was also associated with increased urine density and urinary creatinine and uric acid concentrations [16]. Patients with significant CKD have reduced eGFR, a reduced capacity to concentrate urine, and a decreased capacity to acidify urine $[17$, so they should benefit from a collective reduction in major risk factors for urateinduced adverse events. Moreover, the concomitant use of a XOI with lesinurad reduces the serum urate concentration and therefore the filtered load of uric acid in the glomerulus [18].

Although not derived from this analysis, our empirical approach as precticing clinicians to the renal safety of lesinurad treatment-until further and specifically derived evidence is available-is to encourage adherence to the XOI 
treatment when used in combination with lesinurad, to ensure that adequate fluid intake is maintained, initial evaluation followed by regular surveillance or renal function is untertaken at least using spot urine samples for analysis including abnormals, uric acid, creatinine, density, and $\mathrm{pH}$ for all patients, as we used to do with other uricosurics.

\section{CONCLUSIONS}

The rate of adverse renal events was similar in the placebo and lesinurad $200 \mathrm{mg}$ groups, while the rates of renal failure and nephrolithiasis were numerically lower in the lesinurad $200 \mathrm{mg}$ group than in the placebo group. The risk ratio of sCri with lesinurad versus placebo decreased with worsening renal function.

\section{ACKNOWLEDGEMENTS}

Funding. This work was partially supported by a grant (FPR) from the Asociación de Reumatologos del Hospital de Cruces; no other sources of funding were used. No funding or sponsorship was received for the publication of this article.

Authorship. All named authors meet the International Committee of Medical Journal Editors (ICMJE) criteria for authorship for this article, take responsibility for the integrity of the work as a whole, and have given their approval for this version to be published.

Medical Writing, Editorial, and Other Assistance. All authors shared the preliminary idea. Fernando Perez-Ruiz performed the statistical analysis and wrote a draft paper without any external support. All authors actively discussed the results, significantly contributed to the manuscript, and approved the final version.

Disclosures. Fernando Perez Ruiz: Advisor or speaker fees from Astellas, Grünenthal, Horizon, Japan Tobacco, Logarithm, Menarini.
Tim L. Jansen: Advisor or speaker fees from AbbVie, Celgene, Grünenthal, Novartis.

Anne-Kathrin Tausche: Speaker fees from Berlin Chemie Menarini, Grünenthal, Novartis. Research support from Ardea Biosciences/AstraZeneca, Berlin Chemie Menarini.

Alexander K. So: Advisory board for SOBI, Grünenthal. Speakers board for Menarini, Grünenthal Switzerland.

Pascal Richette: Advisor or speaker fees from Grünenthal, Ipsen Pharma, Menarini France, AstraZeneca.

Frédéric Lioté: Advisor or speaker fees from Grünenthal France, Grünenthal Global, Ipsen Pharma, Menarini France, Novartis France; unrestricted educational grants for supporting annual workshops of the European Crystal Network, Paris: Grünenthal Global, Ipsen Pharma, Menarini France, Novartis, SOBI.

Austin Stack: Advisor or speaker fees from Astellas, Grünenthal, AstraZeneca, and Menarini. Unrestricted educational grant from Menarini.

Compliance with Ethics Guidelines. Data were retrieved from public resources (full prescribing information for Zurampic). This article does not contain any studies with human participants or animals performed by any of the authors.

Open Access. This article is distributed under the terms of the Creative Commons Attribution-NonCommercial 4.0 International License (http://creativecommons.org/licenses/ by-nc/4.0/), which permits any noncommercial use, distribution, and reproduction in any medium, provided you give appropriate credit to the original author(s) and the source, provide a link to the Creative Commons license, and indicate if changes were made.

\section{REFERENCES}

1. Jansen TL, Perez-Ruiz F, Tausche AK, Richette P. International position paper on the appropriate use of uricosurics with the introduction of lesinurad. Clin Rheumatol. 2018;37(12):3159-65. https://doi. org/10.1007/s10067-018-4306-9. 
2. Miner J, Tan PK, Hyndman D, Liu S, Iverson C, Nanavati $P$, et al. Lesinurad, a novel, oral compound for gout, acts to decrease serum uric acid through inhibition of urate transporters in the kidney. Arthritis Res Ther. 2016;18(1):214.

3. Terkeltaub R, Saag KG, Goldfarb DS, Baumgartner S, Schechter BM, Valiyil R, et al. Integrated safety studies of the urate reabsorption inhibitor lesinurad in treatment of gout. Rheumatology (Oxford). 2018;58(1):61-9. https://doi.org/10.1093/rheuma tology/key245.

4. Tausche AK, Alten R, Dalbeth N, Kopicko J, Fung M, Adler S, et al. Lesinurad monotherapy in gout patients intolerant to a xanthine oxidase inhibitor: a 6 month phase 3 clinical trial and extension study. Rheumatology (Oxford). 2017;56(12): 2170-8.

5. Sanchez-Nino MD, Zheng-Lin B, Valino-Rivas L, Sanz AB, Ramos AM, Luno J, et al. Lesinurad: what the nephrologist should know. Clin Kidney J. 2017;10(5):679-87.

6. FDA. Zurampic. Full prescribing information. 2018. https://www.accessdata.fda.gov/drugsatfda_docs/ label/2015/207988lbl.pdf. Accessed 14 Dec 2018

7. EMA. Zurampic: summary of product characteristics. 2018. https://www.ema.europa.eu/documents/ product-information/zurampic-epar-product-infor mation_en.pdf. Accessed 14 Dec 2018

8. Terkeltaub R, Saag KG, Goldfarb DS, Baumgartner S, Schechter BM, Valiyil R, et al. Integrated safety studies of the urate reabsorption inhibitor lesinurad in treatment of gout. Rheumatology (Oxford). 2019;58:61-9.

9. Bardin T, Keenan RT, Khanna PP, Kopicko J, Fung $\mathrm{M}$, Bhakta N, et al. Lesinurad in combination with allopurinol: a randomised, double-blind, placebocontrolled study in patients with gout with inadequate response to standard of care (the multinational CLEAR 2 study). Ann Rheum Dis. 2017;76(5): 811-20.

10. Dalbeth N, Jones G, Terkeltaub R, Khanna D, Kopicko J, Bhakta N, et al. Lesinurad, a selective uric acid reabsorption inhibitor, in combination with febuxostat in patients with tophaceous gout: a phase III clinical trial. Arthritis Rheumatol. 2017;69(9):1903-13.

11. Saag KG, Fitz-Patrick D, Kopicko J, Fung M, Bhakta $\mathrm{N}$, Adler S, et al. Lesinurad combined with allopurinol: a randomized, double-blind, placebo-controlled study in gout patients with an inadequate response to standard-of-care allopurinol (a USbased study). Arthritis Rheumatol. 2017;69(1): 203-12.

12. Cochrane. Cochrane handbook for systematic reviews of interventions, version 5.1.0 [updated March 2011] (9.2.2.2). 2011. https://handbook-5-1. cochrane.org/index.htm\#chapter_9/9_8_chapter_ information.htm. Accessed 14 Dec 2018

13. Wu JY, Chang YT, Lin YC, Lee $\mathrm{CH}$, Loh $\mathrm{EW}, \mathrm{Wu}$ MY, et al. Efficacy and safety of lesinurad in patients with hyperuricemia associated with gout: a systematic review and meta-analysis of randomized controlled trials. Pharmacotherapy. 2018;38: 1106-19.

14. Moon KW, Kim J, Kim JH, Song R, Lee EY, Song YW, et al. Risk factors for acute kidney injury by nonsteroidal anti-inflammatory drugs in patients with hyperuricaemia. Rheumatology (Oxford). 2011;50(12):2278-82.

15. Perez-Ruiz F, Hernandez-Baldizon S, Herrero-Beites AM, Gonzalez-Gay MA. Risk factors associated with renal lithiasis during uricosuric treatment of hyperuricemia in patients with gout. Arthritis Care Res (Hoboken). 2010;62(9):1299-305.

16. Perez-Ruiz F, Calabozo Raluy M, Herrero Beites A, Duruelo J, Ruibal A, Garcia Erauskin G. Utility of urine spot samples for the follow-up of uricosuric therapy. Rev Esp Rheumatol. 2001;28:57-61.

17. Harris RC, Neilson EG. Adaptation of the kidney to renal injury. In: Longo DL, Kasper DL, Jameson JL, Fauci AS, Hauser SL, Loscalzo J, editors. Harrison's principles of internal medicine. 18th ed. New York: McGraw-Hill; 2012. p. 2289-93.

18. Perez-Ruiz F, Calabozo M, Garcia-Erauskin G, Ruibal A, Herrero-Beites AM. Renal underexcretion of uric acid is present in patients with apparent high urinary uric acid output. Arthritis Rheumatol. 2002;47(6):610-3. 